\title{
Plasticity at absolute zero as a fundamental characteristic of dislocation properties
}

\author{
Yuly Milman*, Svitlana Chugunova, Irina Goncharova \\ Institute for Problems of Materials Sciences, National Academy of Sciences of Ukraine, Kiev, Ukraine
}

Email address:

milman@ipms.kiev.ua (Y. Milman)

To cite this article:

Yuly Milman, Svitlana Chugunova, Irina Goncharova. Plasticity at Absolute Zero as a Fundamental Characteristic of Dislocation Properties. International Journal of Materials Science and Applications. Vol. 3, No. 6, 2014, pp. 353-362. doi: 10.11648/j.ijmsa.20140306.22

\begin{abstract}
Values of a plasticity characteristic $\delta_{\mathrm{H}}$ for different materials were determined by the indentation method at cryogenic temperatures. Using the linear dependence $\delta_{\mathrm{H}}(\mathrm{T})$ at low temperatures, the value of $\delta_{\mathrm{H}}$ at $0 \mathrm{~K}$, designated by $\delta_{\mathrm{H}}(0)$, was obtained by the extrapolation method. Values of $\delta_{\mathrm{H}}(0)$ for different materials, namely FCC, HCP and BCC metals, intermetallics, metallic glasses, quasicrystals, ceramics and covalent crystals, are discussed. An analytic expression for a dependence of $\delta_{\mathrm{H}}(0)$ on the parameters of thermoactivated movement of dislocations, melting point and Young's modulus $\mathrm{E}$ is obtained. It is shown that any type of hardening of a crystal and an increase in the Peierls-Nabarro stress $\sigma_{\mathrm{S}}(0)$ reduce $\delta_{\mathrm{H}}(0)$. Only a rise in $\mathrm{E}$ leads to the simultaneous increase in $\sigma_{\mathrm{S}}(0)$ and $\delta_{\mathrm{H}}(0) . \delta_{\mathrm{H}}(0)$ can be considered as a dislocation plasticity in the absence of thermal vibrations of atoms and should be considered together with strength parameters as an important fundamental characteristic of dislocation properties.
\end{abstract}

Keywords: Hardness, Plasticity, Indentation, Dislocations, Plastic Deformation

\section{Introduction}

Some methods for estimation of plasticity of materials by indentation were proposed [1-3 etc]. In the present paper we use the procedure for the determination of plasticity by the indentation method which was elaborated in [3-7] and is used now in a number of studies [8-16 etc]. A plasticity characteristic determined by this method is described by the formula

$$
\delta_{\mathrm{H}}=\frac{\varepsilon_{\mathrm{p}}}{\varepsilon_{\mathrm{t}}}=1-\frac{\varepsilon_{\mathrm{e}}}{\varepsilon_{\mathrm{t}}},
$$

where $\varepsilon_{\mathrm{p}}, \varepsilon_{\mathrm{e}}$ and $\varepsilon_{\mathrm{t}}$ are, respectively, the plastic, elastic and total average strains on the contact area indenter specimen in the direction of the load applied to the indenter; $\varepsilon_{\mathrm{t}}=\varepsilon_{\mathrm{p}}+\varepsilon_{\mathrm{e}}$. This plasticity characteristic (as seen from (1)) is determined by the fraction of the plastic strain in the total elastoplastic strain that agrees well with the physical definition of plasticity [17-18]. The physical definitions of the notion of plasticity are usually given as the susceptibility of a material to undergo permanent deformation under load and do not include the attainment of fracture conditions, which is realized in the determination of the elongation to fracture $\delta$ or the reduction of the cross-sectional area of a specimen to fracture $\psi$ in a tensile test. In indentation, a small volume of a deformed material and the specific character of stress fields decrease the susceptibility to macroscopic fracture and abruptly reduce the ductile-brittle transition temperature $T_{d b}$.

This makes it possible to determine the hardness and the plasticity characteristic of most materials even at cryogenic temperatures.

The procedure for the determination of the plasticity characteristic $\delta_{\mathrm{H}}$ also enables one to assess the plasticity of materials at $0 \mathrm{~K}$ by extrapolation of the curve $\delta_{\mathrm{H}}(\mathrm{T})$ to $0 \mathrm{~K}$. The extrapolation of the values of $\delta_{\mathrm{H}}$ obtained at cryogenic temperatures to $0 \mathrm{~K}$ appears to be possible due to the linear character of the dependence $\delta_{\mathrm{H}}(\mathrm{T})$ at low temperatures.

The linear character of the dependence $\delta_{\mathrm{H}}(\mathrm{T})$ at low temperatures follows from theoretical prerequisites [3] and is substantiated well by experimental results for crystalline materials (see below).

Thus, the possibility to analyze the plasticity of materials in the absence of thermal vibrations of atoms first appeared.

In the present work, the plasticity of different materials at low temperatures, including cryogenic ones, is studied, and the plasticity at $0 \mathrm{~K} \delta_{\mathrm{H}}(0)$ is determined by extrapolation. 
The dependence of $\delta_{\mathrm{H}}(0)$ on the parameters of thermoactivated movement of dislocations and Young's modulus is considered.

The strength characteristics at $0 \mathrm{~K}$ (the theoretical rupture strength and theoretical shear strength for perfect crystals and the Peierls - Nabarro stress for crystals with the dislocation mechanism of deformation) are usually associated with the character of the atomic structure and electronic structure of materials of different type assuming them to be fundamental characteristics $[19,20]$. The authors believe that the experimentally determined plasticity $\delta_{\mathrm{H}}$ at $0 \mathrm{~K}$, which can be considered as dislocation plasticity, typical for a material in the absence of thermal vibrations of atoms, should also be considered together with strength parameters as a fundamental characteristic of dislocation properties.

\section{Plasticity Characteristic $\delta_{\mathrm{H}}$ Determined by the Indentation Method}

The plasticity characteristic defined by expression (1) was proposed in [3]. In this work, the average elastic strain on an contact area indenter - specimen in the direction of an applied load was obtained in the form

$$
\varepsilon_{\mathrm{e}}=-\frac{\mathrm{HM}}{\mathrm{E}}\left(1-\mathrm{v}_{1}-2 \mathrm{v}_{1}^{2}\right)
$$

Here HM is the Meyer hardness, which is considered as the average contact pressure, $E$ is Young's modulus and $v_{1}$ is Poisson's ratio of the investigated material.

The total strain $\varepsilon_{\mathrm{t}}$ was determined for pyramidal indenters in the form

$$
\varepsilon_{\mathrm{t}}=-\ln \sin \gamma
$$

where $\gamma$ is the angle between a face and the axis of the pyramid.

Then, according to equation (1), for a pyramidal indenter, the plasticity characteristic determined in indentation is as follows:

$$
\delta_{\mathrm{H}}=1-\frac{\mathrm{HM}}{\mathrm{E} \varepsilon_{\mathrm{t}}}\left(1-v_{1}-2 v_{1}^{2}\right)
$$

In particular, for a Vickers indenter, in view of $\mathrm{HV}=\mathrm{HM} \cdot \sin \gamma$ and $\gamma=68^{\circ}$, we have

$$
\delta_{\mathrm{H}}=1-14.3\left(1-\mathrm{v}_{1}-2 v_{1}^{2}\right) \frac{\mathrm{HV}}{\mathrm{E}} \text {. }
$$

For Berkovich hardness, in the determination of which a trihedral indenter with an angle $\gamma=65^{\circ}$ is used, and the hardness is determined as the ratio of the load to the projection area of the indent on the surface of the specimen

$$
\delta_{\mathrm{H}}=1-10.2\left(1-v_{1}-2 v_{1}^{2}\right) \frac{\mathrm{HM}}{\mathrm{E}} .
$$

The theory of determination of the plasticity characteristic $\delta_{\mathrm{H}}$ was further developed in [4]. In this work, the condition of incompressibility of a material under an indenter was used only for the calculation of the plastic part of strain $\varepsilon_{p}$, rather than of the total strain, as was done in [3]. That is why the results obtained in [4] can be used in the computation of strains and the plasticity characteristic $\delta_{\mathrm{H}}$ for hard and superhard materials with a larger fraction of the elastic strain in indentation.

For the plastic strain, the following expression was obtained:

$$
\varepsilon_{\mathrm{p}}=-\ln \sqrt{1+\left(\operatorname{ctg} \gamma-\frac{\mathrm{HM}}{\mathrm{kE}}\right)^{2}}
$$

Here $\mathrm{k}=0.565$ for a trihedral and a tetrahedral pyramid and $\mathrm{k}=0.5$ for a conic indenter with an apex angle of $2 \gamma$, $\mathrm{E} *$ is the effective Young's modulus for the contact pair indenter - specimen, and

$$
\frac{1}{E^{*}}=\frac{1-v_{1}^{2}}{E_{1}}+\frac{1-v_{2}^{2}}{E_{2}} .
$$

The subscripts 1 and 2 correspond to the specimen and indenter, respectively.

Using relations (7), (2) and (1), the plasticity characteristic can be calculated more precisely.

In [7], it was shown that the use of the improved theory for most materials changes the value of $\delta_{\mathrm{H}}$ by no more than \pm 0.01 and, thus, does not change the character of the analytic dependence $\delta_{\mathrm{H}}(\mathrm{T})$, which follows from the use of relation (4). That is why, in the present work, in the construction of the dependence $\delta_{\mathrm{H}}(\mathrm{T})$ and in the deduction of the corresponding analytic relations, we use relation (4), which is more convenient for this purpose, (or equation (5), analogous to it, for a Vickers indenter). However, for diamond, Si, Ge and SiC, $\delta_{\mathrm{H}}(0)$ was calculated with equations (1), (2) and (7). Of course, plasticity characteristic $\delta_{\mathrm{H}}$ can not be determined, if indentation is accompanied by intensive fracture.

From equation (1) it is seen that the new plasticity characteristic $\delta_{\mathrm{H}}$ is a dimensionless parameter and may change from 0 (completely elastic strain) to 1 (for the completely plastic behavior of the material). For low-plasticity materials, the parameter $\delta_{\mathrm{H}}$ correlates to some degree with the elongation to fracture $\delta$ determined in tensile tests at $\mathrm{T}>\mathrm{T}_{\mathrm{db}}$ [3]. It is natural that at $\mathrm{T}<\mathrm{T}_{\mathrm{db}}$, the elongation to fracture tends to zero $(\delta \rightarrow 0)$, whereas $\delta_{H}$ has definite values, which characterize the plasticity of the material. As an example, in Fig. 1, temperature dependences of $\delta$ (obtained in a bending test as the elongation to fracture of extended edge fibers) and the plasticity characteristics $\delta_{\mathrm{H}}$ for a WC -6 wt.\% Co hard alloy, constructed on the base of results obtained in [21], is shown.

In [3], it was also experimentally established that the critical 
value $\delta_{\mathrm{HC}}$ exists. The materials that have $\delta_{\mathrm{H}}>\delta_{\mathrm{HC}}$ are ductile in standard mechanical tensile and bending tests $(\delta>0)$, and, for the materials with $\delta_{\mathrm{H}}<\delta_{\mathrm{HC}}$, the elongation in tensile tests $\delta$ usually approaches zero. For pure single phase materials, $\delta_{\mathrm{HC}} \approx 0.9$, and, for composites and coatings, it may be lower [6].

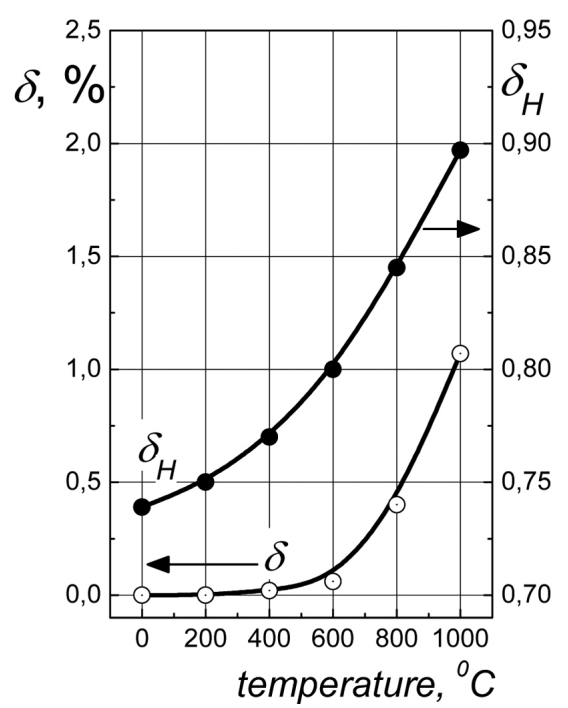

Figure 1. Temperature dependences of the elongation to fracture $\delta$ and plasticity characteristic $\delta_{\mathrm{H}}$ obtained in microindentation for a WC-6 wt.\% Co hard alloy with an average grain size $\mathrm{d}=3 \mu \mathrm{m}$.

Note also that a plasticity characteristic similar to $\delta_{\mathrm{H}}$ can be determined in instrumented indentation when loading and unloading curves are recorded in the coordinates load applied to an indenter $\mathrm{P}$-displacement of the indenter $\mathrm{h}[7,22]$.

In this case, the plasticity characteristic can be written in the form

$$
\delta_{\mathrm{A}}=\frac{\mathrm{A}_{\mathrm{p}}}{\mathrm{A}_{\mathrm{t}}}=1-\frac{\mathrm{A}_{\mathrm{e}}}{\mathrm{A}_{\mathrm{t}}},
$$

where $A_{p}, A_{e}$ and $A_{t}$ are, respectively, the work expended on plastic, elastic and total deformation during the penetration of the indenter; the ratio $A_{e} / A_{t}$ can be determined from the ratio of the area under the unloading curve to the area under the loading curve.

In $[7,22]$, it was shown that $\delta_{\mathrm{H}} \approx \delta_{\mathrm{A}}$ if they are determined with identical indenters under the same load applied to the indenter. An advantage of the characteristic $\delta_{\mathrm{A}}$ is that, in its determination, the preliminary determination of the hardness, Young's modulus and Poisson's ratio is not required, which increases the accuracy of determination of this characteristic. However, unfortunately, at present, data on the determination of $\delta_{\mathrm{A}}$ at cryogenic temperatures are practically absent.

\section{Materials and Experimental Results}

In the present work, in the calculation of the temperature dependence $\delta_{\mathrm{H}}(\mathrm{T})$, a number of results on the temperature dependence of hardness $\mathrm{HV}(\mathrm{T})$ published earlier by the authors [3, 5, 23-25] and a set of additional measurements of $\mathrm{HV}(\mathrm{T})$ are used.

The materials used in these works are highly pure metallic single crystals or annealed polycrystals, natural diamond single crystal, semiconducting silicon and germanium single crystals.

Refractory compounds (WC, $\mathrm{SiC}, \mathrm{NbC}, \mathrm{Al}_{2} \mathrm{O}_{3}, \mathrm{TiC}$ and $\mathrm{ZrC}$ ) were also investigated in the form of single crystals. Metallic glasses (alloys on the base of $\mathrm{Fe}, \mathrm{Co}$ and $\mathrm{Ni}$ ) were studied in the form of ribbons produced by the spinning technique. An $\mathrm{Al}_{63} \mathrm{Cu}_{25} \mathrm{Fe}_{12}$ quasicrystal was obtained by melting followed by annealing at $700{ }^{\circ} \mathrm{C}$, and an $\mathrm{Al}_{70} \mathrm{Pd}_{20} \mathrm{Mn}_{10}$ quasicrystal was investigated in the form of a single quasicrystal.

The low-temperature microhardness was measured in a modernized PMTN unit under a layer of cooling liquid [26]. In this case, the frosting-up of surfaces of specimens with the formation of hard layers of $\mathrm{CO}_{2}$, etc. is ruled out, and homogeneous cooling and the equality of the temperature of the specimen and the temperature of the indenter are provided.

The hardness at temperatures above room temperature was investigated in a vacuum no lower than $10^{-3} \mathrm{~Pa}$ using a unit with a free suspension of an indenter (as in a PMTN unit), which excludes the use of elastic elements, properties of which depend on temperature.

In this case, the load applied to the indenter is determined by the total weight of the indenter and used weights. The value of Young's modulus at cryogenic temperatures was calculated by extrapolation of the experimental data [27-29] taking into account concepts developed in [27].

Temperature dependences of $\delta_{\mathrm{H}}$ for different materials are shown in Figs. 2-8.

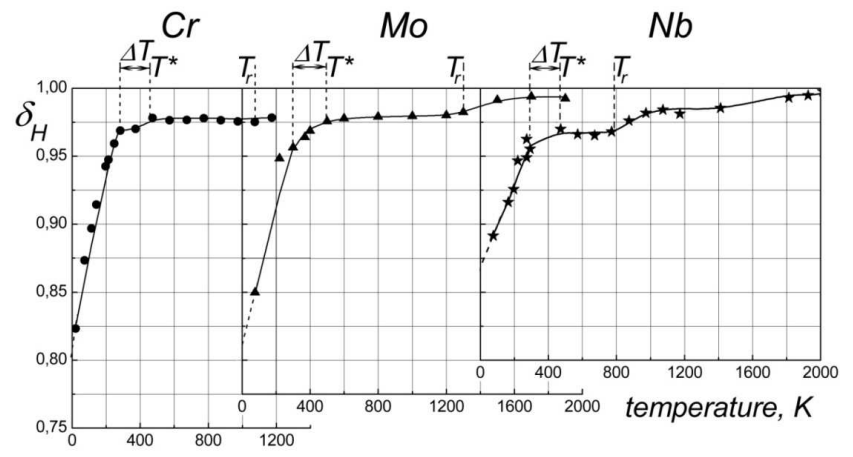

Figure 2. Temperature dependences of the plasticity characteristic $\delta_{\mathrm{H}}$ for $\mathrm{Cr}, \mathrm{Mo}$ and $\mathrm{Nb}$. For Mo and $\mathrm{Cr}$, the values of the characteristic temperature $\mathrm{T} *$ and recrystallization temperature $\mathrm{T}_{\mathrm{r}}$ are indicated. $\Delta \mathrm{T}$ is the temperature range of cold deformation within which the dependence $\mathrm{HM}(\mathrm{T})$ is nonlinear. 


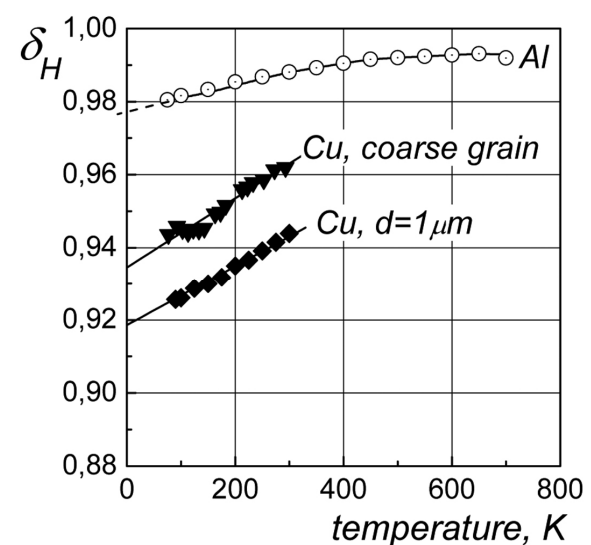

Figure 3. Temperature dependences of the plasticity characteristic $\delta_{\mathrm{H}}$ calculated from data of $\mathrm{HV}(\mathrm{T})$ for aluminum by [30] and for copper by [13, $31]$.

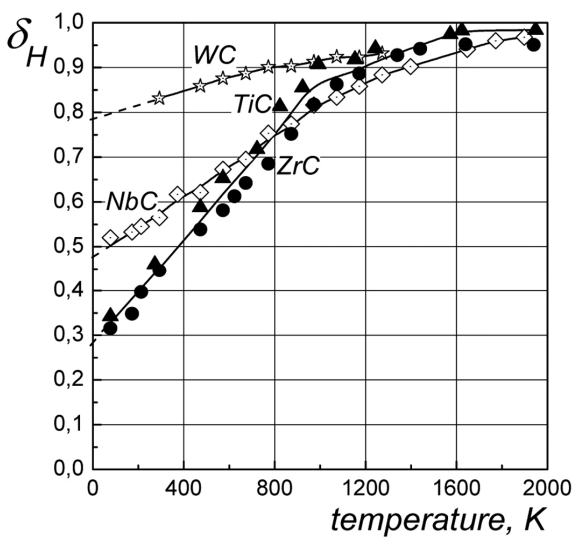

Figure 4. Temperature dependences of the plasticity characteristic $\delta_{\mathrm{H}}$ for refractory compounds $\mathrm{WC}, \mathrm{NbC}, \mathrm{ZrC}$ and $\mathrm{TiC}$.

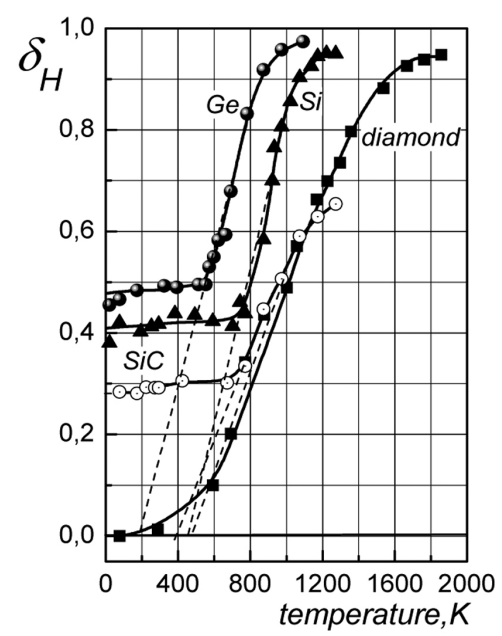

Figure 5. Temperature dependences of the plasticity characteristic $\boldsymbol{\delta}_{\mathrm{H}}$ for single crystals: diamond (plane (001)), Si (plane (111)), Ge (plane (111)) and $\mathrm{SiC}$ (plane (0001)). The extrapolation of $\delta_{\mathrm{H}}(\mathrm{T})$ from the region of dislocation mechanism of deformation (dotted lines) was performed to determine temperatures $\mathrm{T}_{\mathrm{C}}$ at which $\delta_{\mathrm{H}}=0$ in the absence of a phase transition in diamond, $\mathrm{Si}$ and Ge during indentation. For SiC, the low-temperature region, in which the leading mechanism of formation of an indent is fracture, is ignored to determine temperature $\mathrm{T}_{\mathrm{C}}$

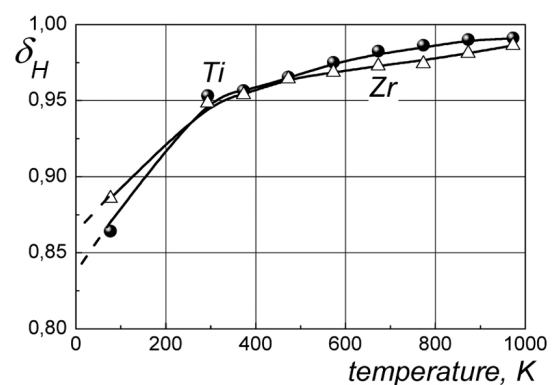

Figure 6. Temperature dependences of the plasticity characteristic $\delta_{\mathrm{H}}$ for Ti and $Z r$.

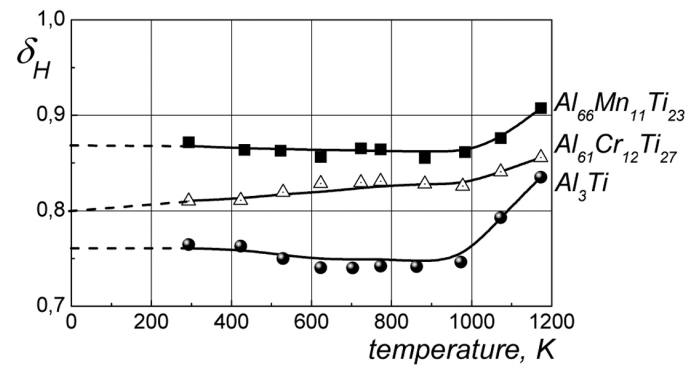

Figure 7. Temperature dependences of the plasticity characteristic $\delta_{\mathrm{H}}$ for intermetallics.

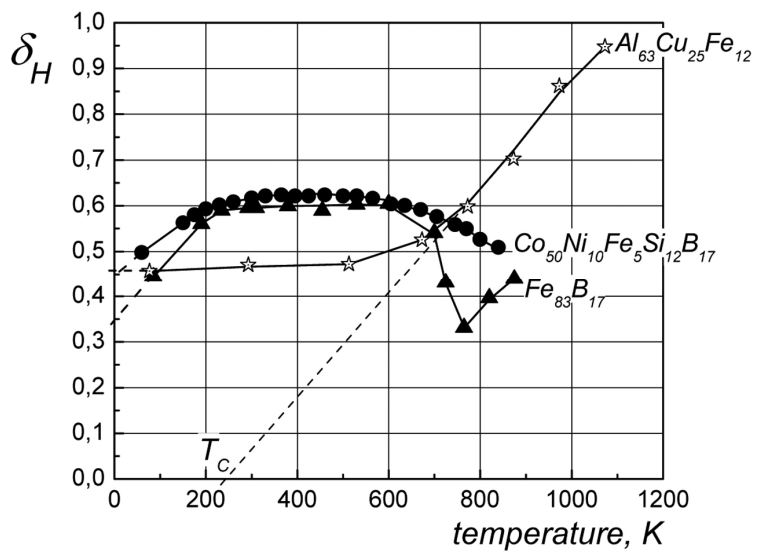

Figure 8. Temperature dependence of the plasticity characteristic $\delta_{\mathrm{H}}$ for metallic glasses $\mathrm{Co}_{56} \mathrm{Ni}_{10} \mathrm{Fe}_{5} \mathrm{Si}_{12} \mathrm{~B}_{17}$ and $\mathrm{Fe}_{83} \mathrm{~B}_{17}$ and an $\mathrm{Al}_{63} \mathrm{Cu}_{25} \mathrm{Fe}_{12}$ quasicrystal. $T_{C}$ is the temperature at which $\delta_{H}$ of the $\mathrm{Al}_{63} \mathrm{Cu}_{25} \mathrm{Fe}_{12}$ quasicrystal would be equal to zero if the phase transition was absent in the process of indentation.

In Table 1, values of $\delta_{\mathrm{H}}$ at $20{ }^{\circ} \mathrm{C}$ and values of $\delta_{\mathrm{H}}$ at $0 \mathrm{~K}$, obtained by extrapolation of the curves $\delta_{\mathrm{H}}(\mathrm{T})$ to $0 \mathrm{~K}$, are presented.

\section{Influence of Temperature on the Plasticity Characteristic $\boldsymbol{\delta}_{\mathrm{H}}$}

For the description of the temperature dependence of the hardness HM, it is most expedient to use the theory of the temperature dependence of the conventional yield strength $\sigma_{\mathrm{S}}$ determined at a fixed degree of strain $\varepsilon_{\mathrm{p}}^{*}[32,33]$.

According to this theory, for crystals with a high Peierls Nabarro stress in a rather wide temperature range adjacent to 
$0 \mathrm{~K}$, the temperature dependence of the conventional yield strength is described by the expression

$$
\sigma_{\mathrm{S}}=\frac{\mathrm{U}-\mathrm{kT} \ln \frac{\mathrm{M}}{\dot{\varepsilon}}}{\mathrm{V}}=\sigma_{\mathrm{S}}(0)-\frac{\mathrm{kT}}{\mathrm{V}} \ln \frac{\mathrm{M}}{\dot{\varepsilon}} .
$$

Here $U$ is the activation energy of movement of dislocations, $\mathrm{V}$ is the activation volume, $\mathrm{M}$ is a material constant, $\dot{\varepsilon}$ is the strain rate and $\sigma_{\mathrm{S}}(0)$ is the yield stress at 0 $\mathrm{K}$.

According to Tabor [34] and Johnson [35], we assume

$$
\mathrm{HM}=\mathrm{C} \cdot \sigma_{\mathrm{S}},
$$

where $\mathrm{C} \approx$ const.

Using relations (4), (10) and (11) and ignoring the temperature dependence of Young's modulus in comparison with $\sigma_{\mathrm{S}}(\mathrm{T})$, we obtain

$$
\delta_{\mathrm{H}}=\delta_{\mathrm{H}}(0)+\frac{\mathrm{AT}}{\mathrm{VE}},
$$

where $\delta_{\mathrm{H}}(0)$ is the plasticity at $0 \mathrm{~K}$ and

$$
\begin{aligned}
\delta_{\mathrm{H}}(0) & =1-\frac{\mathrm{C} \sigma_{\mathrm{S}}(0)}{\mathrm{E} \varepsilon_{\mathrm{t}}}\left(1-v_{1}-2 v_{1}^{2}\right)= \\
& =1-\frac{\operatorname{HM}(0)}{\mathrm{E} \varepsilon_{\mathrm{t}}}\left(1-v_{1}-2 v_{1}^{2}\right), \\
\mathrm{A} & =\frac{\mathrm{Ck}}{\varepsilon_{\mathrm{t}}}\left(1-v_{1}-2 v_{1}^{2}\right) \ln \frac{\mathrm{M}}{\dot{\varepsilon}} .
\end{aligned}
$$

It is seen from above given results that theory and experimental results indicate the linear dependence of $\delta_{\mathrm{H}}(\mathrm{T})$ at the cryogenic temperatures. For this reason we interpolate this dependence by linear function. For metals the Standard deviation of the fit (SD) was lower than $2 \%$. For other materials SD was not more than $3 \%$. $\delta_{\mathrm{H}}(0)$ was obtained by

\begin{tabular}{|c|c|c|c|c|c|c|c|c|c|c|c|}
\hline Materials & & $\begin{array}{l}\text { HV, } \\
\text { GPa }\end{array}$ & $\mathrm{E}, \mathbf{G P a}$ & $v$ & $\delta_{\mathrm{H}}$ & $\mathrm{HV}(0), \mathbf{G P a}$ & $\begin{array}{l}\mathrm{HV}_{\mathrm{t}}(0), \\
\text { GPa }\end{array}$ & $\begin{array}{l}\mathrm{HV}_{\mathrm{a}}, \\
\mathbf{G P a}\end{array}$ & $\delta_{H}(0)$ & $\delta_{\mathrm{HW}}$ & $\begin{array}{l}\mathrm{T}_{\mathrm{C}}, \\
\mathbf{K}\end{array}$ \\
\hline \multirow{3}{*}{ FCC metals } & $\mathrm{Al}^{*}$ & 0.16 & 71 & 0.35 & 0.99 & 0.35 & & & 0.98 & & \\
\hline & $\mathrm{Cu}$ (coarse grain) & 0.80 & 129 & 0.34 & 0.96 & 1.46 & & & 0.94 & & \\
\hline & $\mathrm{Cu}(\mathrm{d} \approx 1 \mu \mathrm{m})$ & 1.18 & 129 & 0.34 & 0.94 & 1.8 & & & 0.92 & & \\
\hline \multirow{4}{*}{ BCC metals } & $\mathrm{Cr}^{*}$ & 1.30 & 298 & 0.31 & 0.97 & 8 & 7.13 & 0.87 & 0.81 & 0.98 & \\
\hline & Mo (111) & 1.85 & 324 & 0.293 & 0.96 & 8.5 & 7.75 & 0.75 & 0.81 & 0.98 & \\
\hline & $\mathrm{Nb}^{*}$ & 1.13 & 104 & 0.397 & 0.96 & 3.6 & 2.81 & 0.79 & 0.87 & 0.97 & \\
\hline & $\mathrm{Fe}^{*}$ & 1.40 & 211 & 0.28 & 0.95 & 3.2 & 1.8 & 1.4 & 0.88 & 0.95 & \\
\hline \multirow{2}{*}{ HCP metals } & $\mathrm{Ti}^{*}$ & 1.03 & 120 & 0.36 & 0.95 & 3.7 & 3.56 & 0.14 & 0.84 & 0.96 & \\
\hline & $\mathrm{Zr} *$ & 1.07 & 98 & 0.38 & 0.95 & 3.0 & 2.72 & 0.28 & 0.86 & 0.96 & \\
\hline \multirow{3}{*}{ Intermetallics } & $\mathrm{Al}_{3} \mathrm{Ti}$ & 4.94 & 156 & 0.3 & 0.76 & 5.0 & & & 0.76 & & \\
\hline & $\mathrm{Al}_{61} \mathrm{Cr}_{12} \mathrm{Ti}_{27}$ & 3.20 & 178 & 0.19 & 0.81 & 3.5 & & & 0.80 & & \\
\hline & $\mathrm{Al}_{66} \mathrm{Mn}_{11} \mathrm{Ti}_{23}$ & 2.04 & 168 & 0.19 & 0.87 & 2.1 & & & 0.87 & & \\
\hline \multirow{3}{*}{$\begin{array}{l}\text { Metallic } \\
\text { glasses }\end{array}$} & $\mathrm{Fe}_{83} \mathrm{~B}_{17}$ & 9.3 & 171 & 0.3 & 0.60 & 16.2 & 7.2 & 9.0 & 0.35 & 0.60 & \\
\hline & $\mathrm{Fe}_{40} \mathrm{Ni}_{38} \mathrm{Mo}_{4} \mathrm{~B}_{18}$ & 7.4 & 152 & 0.3 & 0.64 & 10.7 & 3.5 & 7.2 & 0.52 & 0.64 & \\
\hline & $\mathrm{Co}_{50} \mathrm{Ni}_{10} \mathrm{Fe}_{5} \mathrm{Si}_{12} \mathrm{~B}_{17}$ & 8.6 & 167 & 0.3 & 0.62 & 13.0 & 4.7 & 8.3 & 0.44 & 0.62 & \\
\hline \multirow{2}{*}{ Quasicrystals } & $\mathrm{Al}_{63} \mathrm{Cu}_{25} \mathrm{Fe}_{12}$ & 7.43 & 113 & 0.28 & 0.47 & 7.65 & & & $0 / 0.45^{* *}$ & & 240 \\
\hline & $\mathrm{Al}_{70} \mathrm{Pd}_{20} \mathrm{Mn}_{10}$ & 7.0 & 200 & 0.28 & 0.72 & 9.75 & 3.05 & 6.7 & 0.61 & 0.72 & \\
\hline \multirow{6}{*}{ Ceramics } & $\alpha-\operatorname{SiC}(0001)$ & 34 & 457 & 0.22 & 0.29 & 35 & 27.6 & 7.4 & $0 / 0.28 * *$ & 0.65 & 400 \\
\hline & $\mathrm{Al}_{2} \mathrm{O}_{3}(0001)$ & 20.4 & 323 & 0.23 & 0.40 & 27 & 25.6 & 1.4 & 0.21 & 0.90 & \\
\hline & $\mathrm{TiC}(100)$ & 24 & 465 & 0.191 & 0.46 & 33.2 & 31.2 & 2 & 0.28 & 0.95 & \\
\hline & $\mathrm{ZrC} \mathrm{(100)}$ & 22 & 410 & 0.196 & 0.45 & 29 & 27 & 2 & 0.28 & 0.94 & \\
\hline & $\mathrm{NbC}(100)$ & 24 & 550 & 0.21 & 0.56 & 29 & 24.5 & 4.5 & 0.48 & 0.91 & \\
\hline & WC (0001) & 16.7 & 700 & 0.31 & 0.83 & 20.7 & 14.2 & 6.5 & 0.79 & 0.93 & \\
\hline \multirow{3}{*}{$\begin{array}{l}\text { Covalent } \\
\text { crystals }\end{array}$} & Diamond (001) & 131.5 & 1200 & 0.1 & 0.012 & 167 & 160.5 & 6.5 & 0 & 0.94 & 480 \\
\hline & Si (111) & 10.5 & 160 & 0.22 & 0.42 & 10.8 & & & $0 / 0.41^{* *}$ & 0.95 & 400 \\
\hline & Ge (111) & 7.2 & 130 & 0.21 & 0.49 & 8.0 & & & $0 / 0.45^{* *}$ & 0.97 & 190 \\
\hline
\end{tabular}
extrapolation of the obtained linear dependence of $\delta_{H}(T)$ to $0 \mathrm{~K}$.

Table 1. Values of the hardness $\mathrm{HV}$, Young's modulus $\mathrm{E}$, Poisson's ratio $\mathrm{v}$ at $293 \mathrm{~K}$, hardness $\mathrm{HV}(0)$ at $0 \mathrm{~K}$, values of $\mathrm{HV}_{\mathrm{t}}(0)$ and $\mathrm{HV}_{\mathrm{a}}$, the plasticity characteristic at $293 K \delta_{\mathrm{H}}$, at $0 \mathrm{~K} \delta_{\mathrm{H}}(0)$ and in the temperature range of warm deformation $\delta_{\mathrm{HW}} \cdot \mathrm{T}_{\mathrm{C}}$ is the temperature at which $\delta_{\mathrm{H}}=0$ under the dislocation mechanism of deformation in the absence of phase transitions in diamond, Si, Ge and an $\mathrm{Al}_{63} \mathrm{Cu}_{25} \mathrm{Fe}_{12}$ quasicrystal.

*Polycrystal,

** In the numerator, values of $\delta_{\mathrm{H}}(0)$ obtained under the dislocation mechanism of deformation are presented, and, in the denominator, values obtained with consideration for the phase transition in indentation or the change of the mechanism of deformation in indentation (SiC) are given. 


\section{Relation of the Plasticity Characteristic $\delta_{\mathrm{H}}(0)$ to Parameters of Thermoactivated Movement of Dislocations}

Typical dependence $\delta_{H}(T)$ in the temperature ranges of cold, warm and hot deformation is shown in Fig. 9 according to $[3,5,36]$. Characteristic deformation temperature $\mathrm{T} *$ and recrystallization temperature $T_{r}$ are the boundaries between temperature ranges. Here $\mathrm{T} *$ is the temperature below which the Peierls - Nabarro stress is essential and yield stress increases sharply and $\delta_{\mathrm{H}}$ decreases with the temperature diminution [32, 37]. In the temperature range of warm deformation, the plasticity characteristic is $\delta_{\mathrm{HW}} \approx$ const, and, for the majority of perfect crystalline materials, $\delta_{\mathrm{HW}} \approx 0.90-0.98$ (Fig. 9, Table 1).

For the approximate solution of the stated problem, we assume that, in the considered temperature range, the dependence $\delta_{H}(T)$ is described by two straight lines.

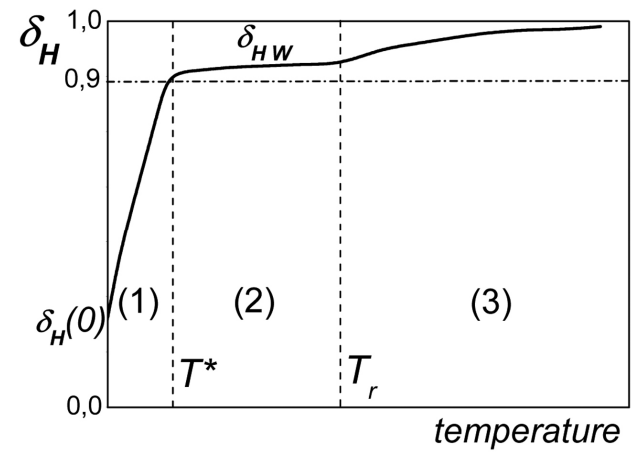

Figure 9. Scheme of the temperature dependence of the plasticity $\delta_{\mathrm{H}}$ in regions of cold (1), warm (2) and hot (3) deformation.

In this case, the point of intersection of these straight lines coincides approximately with the characteristic temperature of deformation $\mathrm{T} *$ (or more precisely, it corresponds to $\mathrm{T} *-\Delta \mathrm{T}$, where $\Delta \mathrm{T}$ is the temperature range of cold deformation within which the dependence $\operatorname{HM}(\mathrm{T})$ is nonlinear, see Fig. 2).

Then, using expression (12), we get

$$
\delta_{\mathrm{H}}(0)=\delta_{\mathrm{HW}}-\frac{\mathrm{A}(\mathrm{T} *-\Delta \mathrm{T})}{\mathrm{VE}} .
$$

From this expression it is seen that materials with a high temperature $\mathrm{T} *$ must have a lower value of $\delta_{\mathrm{H}}(0)$. Naturally, the ratio A/VE is also crucial for the magnitude $\delta_{\mathrm{H}}(0)$.

From $[32,37]$ it follows that the temperature $\mathrm{T} *$ can be represented in the form

$$
\mathrm{T} *=\frac{1}{\sqrt{21}}\left(\frac{\mathrm{UT}_{\mathrm{m}}}{\mathrm{k}}\right)^{1 / 2},
$$

where $U$ is the activation energy of movement of dislocations, $\mathrm{T}_{\mathrm{m}}$ is the melting point and $\mathrm{k}$ is the Boltzmann constant.

Consequently,

$$
\delta_{\mathrm{H}}(0)=\delta_{\mathrm{HW}}-\left(\frac{\left(\mathrm{UT}_{\mathrm{m}}\right)^{1 / 2}}{\sqrt{21} \mathrm{k}^{1 / 2}}-\Delta \mathrm{T}\right) \frac{\mathrm{A}}{\mathrm{VE}} .
$$

\section{Discussion of Experimental Results}

It is seen from Figs. 2-7 that, $\delta_{\mathrm{H}}$ increases with the growth of temperature in the whole investigated temperature range for crystalline materials in contrast to the elongation to fracture $\delta$, (the exceptions are some intermetallics with anomalous temperature dependence of the yield stress [38]). For metallic glasses, a rise in temperature to the crystallization temperature usually leads to a decrease in $\delta_{\mathrm{H}}$ (Fig. 8). In the curves of the dependence $\delta_{\mathrm{H}}(\mathrm{T})$ for crystalline materials, three temperature regions can be distinguished (Fig. 9). These are regions of cold, warm and hot deformation $[5,36,39]$. In the $\delta_{\mathrm{H}}(\mathrm{T})$ curves, these regions are most pronounced for refractory metals with a BCC lattice (Fig. 2). The boundary between the temperature intervals of cold and warm deformations is the characteristic temperature of deformation $\mathrm{T} *$ [39] and the boundary between the temperature regions of warm and hot deformations is the recrystallization temperature $T_{r}$. Features of the behavior of $\delta_{\mathrm{H}}(\mathrm{T})$ in different temperature intervals were discussed in [3, 5]. For the present work, the behavior of $\delta_{\mathrm{H}}$ in the temperature range of cold deformation is of particular importance. As is seen from Figs. 2-8, for all investigated materials, excepting $\mathrm{Si}$, Ge and the $\mathrm{Al}_{63} \mathrm{Cu}_{25} \mathrm{Fe}_{12}$ quasicrystal (where the indentation process is accompanied by a phase transition [40-43]), an abrupt decrease in $\delta_{\mathrm{H}}$ with decreasing temperature is observed. Note that, in the temperature region adjacent to $0 \mathrm{~K}$, the dependence $\delta_{H}(T)$ is linear, which agrees with equation (12). The formation of practically athermal regions (adjacent to $0 \mathrm{~K}$ ) of the dependences $\mathrm{H}(\mathrm{T})$ and $\delta(\mathrm{T})$ may be caused by factors such as the phase transition in the process of indentation [40], the replacement of the sliding mechanism of deformation by the twinning mechanism and by the fact that the mechanism of fracture rather than the mechanism of plastic deformation may become the leading mechanism of formation of a hardness indent in low-plasticity materials at low temperatures [41]. For intermetallics, a weak dependence $\operatorname{HM}(\mathrm{T})$ and, hence, a weak dependence $\delta_{\mathrm{H}}(\mathrm{T})$ are characteristic (Fig. 7).

In the considered temperature region of cold deformation, for BCC metals and covalent crystals, a random distribution of dislocations is typical. Here, dislocation "locks" are unstable due to a high level of external stresses, and dislocation subboundaries hardly form. Strain hardening is caused by the interaction of mobile dislocations with forest dislocations, and the mobility of dislocations in crystals with a significant fraction of the covalent component in the interatomic bond is 
determined by the thermally activated overcoming of Peierls barriers and decreases with decreasing temperature. That is why, as temperature decreases, plastic deformation is hindered, the hardness HM increases, and the plasticity characteristic $\delta_{\mathrm{H}}$ decreases.

From expression (13) it is evident that the plasticity at $0 \mathrm{~K}$ $\delta_{\mathrm{H}}(0)$ diminishes with increasing $\sigma_{\mathrm{S}}(0)$ and rises with increasing Young's modulus E and Poisson's ratio $v$. The yield strength at $0 \mathrm{~K}$ usually consists of two components, namely a thermal component $\sigma_{\mathrm{St}}$ and an athermal component $\sigma_{\mathrm{Sa}}$

$$
\sigma_{\mathrm{S}}(0)=\sigma_{\mathrm{St}}+\sigma_{\mathrm{Sa}}
$$

For crystals with a covalent component in the interatomic bond, $\sigma_{\mathrm{St}}$ corresponds to the Peierls - Nabarro stress, and $\sigma_{\mathrm{Sa}}$ is determined by the structural factors and hardening caused by alloying elements, impurity elements and disperse particles of the second phase.

From expressions (13) and (15) it is clearly seen that an increase in the Peierls - Nabarro stress $\sigma_{\mathrm{St}}(0)$, which can be considered to be a fundamental property of a perfect crystal with a covalent component of the interatomic bond, reduces the plasticity $\delta_{\mathrm{H}}(0)$.

The value of $\delta_{\mathrm{H}}(0)$ for a perfect crystal, in which $\sigma_{\mathrm{Sa}}$ is negligibly small, can also be considered to be a fundamental characteristic of the material under the dislocation mechanism of deformation.

From expressions (13) and (15) it is also seen that an increase in $\sigma_{\mathrm{Sa}}(0)$ as a result of an increase in the dislocation density, a decrease in the grain size, solid solution hardening by alloying elements and disperse hardening by particles of the second phase also reduces $\delta_{\mathrm{H}}(0)$.

The hardness at $0 \mathrm{~K}$ can also be represented in the form of two components

$$
\mathrm{H}(0)=\mathrm{HV}_{\mathrm{t}}(0)+\mathrm{HV}_{\mathrm{a}}
$$

In Table 1, values of $\mathrm{HV}_{\mathrm{t}}$ and $\mathrm{HV}_{\mathrm{a}}$ for a number of materials are presented. From the values of $\mathrm{HV}_{\mathrm{t}}$ and $\mathrm{HV}_{\mathrm{a}}$ one can assess the contribution of lattice retardation of dislocations $\left(\operatorname{HV}_{\mathrm{t}}(0)\right)$ and the contribution of the structural and impurity factors $\left(\mathrm{HV}_{\mathrm{a}}\right)$ on the value of $\delta_{\mathrm{H}}(0)$.

It is very important to note that Young's modulus $\mathrm{E}$, which is the most important parameter determining the Peierls Nabarro stress and the theoretical strength of crystals [19, 20], enters also in expression (13), and an increase in E leads not only to an increase in the theoretical strength, but also to an increase in the plasticity $\delta_{\mathrm{H}}(0)$.

From expression (12) it follows that, in the low-temperature region, the parameter $\delta_{\mathrm{H}}$ must rise linearly with temperature, which is observed in practice. In this case,

$$
\frac{\mathrm{d} \delta_{\mathrm{H}}}{\mathrm{dT}}=\frac{\mathrm{A}}{\mathrm{VE}},
$$

i.e., Young's modulus $\mathrm{E}$ and the activation volume $\mathrm{V}$ are the most important parameters that cause an increase in $\delta_{H}$ with temperature.

Expression $(14 \mathrm{a})$ relates $\delta_{\mathrm{H}}(0)$ to the parameters of thermoactivated movement of dislocations ( $\mathrm{U}$ and $\mathrm{V}$ ), melting point $\mathrm{T}_{\mathrm{m}}$ and $\mathrm{E}$. From this expression it follows that an increase in the height of potential barriers $U$ and a decrease in their width, which can be characterized by $V$, leads to a decrease in $\delta_{\mathrm{H}}(0)$. An increase in the melting point $\mathrm{T}_{\mathrm{m}}$ also decreases $\delta_{\mathrm{H}}(0)$. Only an increase in the modulus of elasticity E and Poisson's ratio $v$ lead to a rise in $\delta_{\mathrm{H}}(0)$.

From Table 1 and Fig. 3 it is seen that, in FCC metals (Al and $\mathrm{Cu}$ ), the value of $\delta_{\mathrm{H}}$ at room temperature is substantially larger than the critical value $\delta_{\mathrm{HC}}$. Moreover, it is known that these metals have high plasticity to fracture $\delta$ not only at room temperature, but also at cryogenic temperatures, including the liquid-nitrogen temperature and even the liquid-helium temperature [13]. Estimation indicates that, for these metals, $\delta_{\mathrm{H}}(0)>\delta_{\mathrm{HC}}$ even at $0 \mathrm{~K}$. The reserves of plasticity in these metals appear to be so significant that, even after grain refining to $1 \mu \mathrm{m}, \delta_{\mathrm{H}}>\delta_{\mathrm{HC}}$ not only at room temperature, but also at temperatures close to $0 \mathrm{~K}$ (see also Table 1). However, in nanostructured copper, at a grain size $\mathrm{d} \approx 25 \mathrm{~nm}$, even at room temperature, $\delta_{\mathrm{H}} \approx \delta_{\mathrm{HC}}$, and the plasticity to fracture $\delta$ is only $1-2 \%$ [44].

For highly pure BCC metals, the inequality $\delta_{\mathrm{H}}>\delta_{\mathrm{HC}}$ is also satisfied at room temperature, i.e., they have some plasticity in tensile tests. However, as temperature decreases, due to the significant fraction of the covalent component in the interatomic bond and a high Peierls - Nabarro stress in these metals, the yield strength and hardness increase drastically [32], whereas the plasticity characteristic $\delta_{\mathrm{H}}$ decreases abruptly (Fig. 2), and, at $0 \mathrm{~K}, \delta_{\mathrm{H}}(0)<\delta_{\mathrm{HC}}$, i.e., in these metals, as temperature decreases to a value lower than room temperature, the ductile-brittle transition occurs. In the present work, we do not consider commercially pure BCC metals and alloys on the base of them, in which the ductile-brittle transition temperature may be higher than room temperature (particularly in VI-A group metals, namely $\mathrm{Cr}$, Mo and $\mathrm{W}$ [32]). Much the same situation is observed for HCP metals. In Table 1, results for pure titanium and zirconium are presented. At room temperature, $\delta_{\mathrm{H}}>\delta_{\mathrm{HC}}$, but at $0 \mathrm{~K}, \delta_{\mathrm{H}}(0)<\delta_{\mathrm{HC}}$.

In covalent crystals, namely diamond, silicon and germanium, even at room temperature, $\delta_{\mathrm{H}}<\delta_{\mathrm{HC}}$. In these crystals, as temperature decreases, the most drastic increases in the yield strength and hardness are observed. However, in a wide temperature interval adjacent to $0 \mathrm{~K}$, in $\mathrm{Si}$ and $\mathrm{Ge}$, indentation is accompanied by the semiconductor $\rightarrow$ metal phase transition, and the hardness has a nearly constant value in a wide temperature interval adjacent to $0 \mathrm{~K}$ and does not reflect the yield stress [40,45-49]. That is why, to assess $\delta_{H}$ in these crystals under dislocation mechanism of deformation, 
the extrapolation of the dependence $\delta_{H}(T)$ can be performed only from a region of higher temperatures where the mechanism of deformation has the dislocation character. Such an extrapolation indicates that, a value $\delta_{\mathrm{H}}=0$ is attained in these crystals at a certain temperature $\mathrm{T}_{\mathrm{C}}$, which is much higher than $0 \mathrm{~K}$ (see Fig. 5). The values of $\mathrm{T}_{\mathrm{C}}$ for these crystals are also presented in Table 1, in which it is shown that, in these crystals, $\delta_{\mathrm{H}}(0)$ would be equal to 0 under the dislocation mechanism of deformation, but, actually, as a consequence of the phase transition, $\delta_{\mathrm{H}}(0)$ is much higher.

In refractory compounds with a significant fraction of the covalent component of the interatomic bond $\left(\mathrm{SiC}, \mathrm{Al}_{2} \mathrm{O}_{3}, \mathrm{TiC}\right.$, $\mathrm{ZrC}, \mathrm{NbC}$ and $\mathrm{WC}$ ), $\delta_{\mathrm{H}}<\delta_{\mathrm{HC}}$ even at $20{ }^{\circ} \mathrm{C}$, and, as temperature decreases, $\delta_{\mathrm{H}}$ further diminishes (Fig. 4) so that, for most of these crystals, $\delta_{H}(0)$ is very low. Note that tungsten carbide WC has a higher value of $\delta_{\mathrm{H}}$ than those of other considered compounds both at room temperature and at $0 \mathrm{~K}$, which can be explained by a large value of Young's modulus $\mathrm{E}$ and a lower ratio $\mathrm{HM} / \mathrm{E}$. Evidently, high value of $\delta_{\mathrm{H}}$ (higher than those of other carbides) provides the efficient operation of WC in hard alloys.

For silicon carbide $\mathrm{SiC}$, the low-temperature athermal segment of the dependence $H(T)$ is due to the change of the mechanism of deformation, i.e., at low temperatures, fracture rather than plastic deformation becomes the leading mechanism of formation of an indent in indentation [41].

For the studied intermetallic $\mathrm{Al}_{3} \mathrm{Ti}, \delta_{\mathrm{H}}$ is low at $20^{\circ} \mathrm{C}$, and this intermetallic is brittle. The alloying of $\mathrm{Al}_{3} \mathrm{Ti}$ with $\mathrm{Cr}$ or $\mathrm{Mn}$ leads to the formation of the cubic $\mathrm{L}_{2}$ structure and an increase in the plasticity $\delta_{\mathrm{H}}$, which, however, remains much lower than $\delta_{\mathrm{HC}}$. The temperature dependence of the yield strength of these intermetallics is weak, and, as seen from Fig. 7 and Table $1, \delta_{\mathrm{H}}$ decreases slightly as temperature decreases to $0 \mathrm{~K}[50]$.

The low value of $\delta_{\mathrm{H}}$ in metallic glasses, is mainly due to the athermal component of the yield stress $\sigma_{\mathrm{Sa}}$ (and the athermal component of the hardness $\mathrm{H}_{\mathrm{a}}$ ), which, for these materials, is large and usually larger than the thermal component (in contrast to BCC metals and covalent crystals). The amorphous state can be considered as a limit defective state, which leads to a high value of $\sigma_{\mathrm{Sa}}$ in these materials [25].

The studied quasicrystals $\mathrm{Al}_{63} \mathrm{Cu}_{25} \mathrm{Fe}_{12}$ and $\mathrm{Al}_{70} \mathrm{Pd}_{20} \mathrm{Mn}_{10}$ are also brittle at room temperature, and, for them, $\delta_{\mathrm{H}}<\delta_{\mathrm{HC}}$. At the same time, in indentation, in the $\mathrm{Al}_{63} \mathrm{Cu}_{25} \mathrm{Fe}_{12}$ alloy, a phase transition to a more plastic, so-called approximant phase is observed [43]. As a result, here, as in the case of covalent crystals, there exists a wide low-temperature range where $\mathrm{HM} \approx$ const and $\delta_{\mathrm{H}} \approx$ const. If the phase transition did not occur in this quasicrystal, $\delta_{\mathrm{H}}$ would be equal to zero even at $240 \mathrm{~K}$ (Fig. 8 and Table 1).

\section{Conclusions}

An analytic expression for plasticity at $0 \mathrm{~K} \delta_{\mathrm{H}}(0)$ was obtained, from which it follows that an increase in the Peierls - Nabarro stress and any type of athermal hardening of a material (an increase in the dislocation density, a decrease in the grain size, solid solution hardening with alloying elements, dispersion hardening, etc.), lead to a decrease in the plasticity characteristic at $0 \mathrm{~K} \delta_{\mathrm{H}}(0)$. An analytic connection of the plasticity at $0 \mathrm{~K} \delta_{H}(0)$ to the parameters of the thermally activated dislocation motion (activation energy of dislocations movement $\mathrm{U}$ and activation volume $\mathrm{V}$ ), melting point $\mathrm{T}_{\mathrm{m}}$ and Young's modulus $\mathrm{E}$ was determined. An increase in the height of potential barriers ( U ), a decrease in the width ( V) and a rise in $T_{m}$ lead to a decrease in $\delta_{H}(0)$. At the same time, a rise in Young's modulus $\mathrm{E}$, which determines strength properties, leads to an increase in $\delta_{H}(0)$, as well. The real values of $\delta_{\mathrm{H}}(0)$ for a number of FCC, BCC and HCP metals of high purity, refractory compounds, covalent crystals, intermetallic compounds, metallic glasses and quasicrystals were analyzed.

The studied materials can be arranged in order of decreasing value of $\delta_{\mathrm{H}}(0)$ as follows:

FCC metals;

$\mathrm{BCC}$ and $\mathrm{HCP}$ metals;

intermetallics;

metallic glasses;

quasicrystals;

refractory compounds (WC is distinguished noticeably by its increased value of $\delta_{\mathrm{H}}(0)$ and approaches intermetallics in terms of this parameter);

covalent crystals: diamond, $\mathrm{Si}$, and Ge, for which $\delta_{\mathrm{H}}(0)=$ 0 under the dislocation mechanism of deformation without phase transition during indentation.

For FCC metals, a high level of plasticity at $0 \mathrm{~K}$, which is sufficient for the plastic behavior in tensile tests, is retained. In BCC and HCP metals, $\delta_{\mathrm{H}}(0)$ is decreased so that, in tensile tests in the vicinity of $0 \mathrm{~K}$, these materials are brittle. However, for these metals, the value of $\delta_{\mathrm{H}}(0)$ is much higher than those of intermetallics, refractory compounds (e.g., carbides) and covalent crystals.

For $\mathrm{Si}, \mathrm{Ge}$, diamond and an $\mathrm{Al}_{63} \mathrm{Cu}_{25} \mathrm{Fe}_{12}$ quasicrystal, the extrapolation of $\delta_{\mathrm{H}}$ from the region of dislocation plasticity to low temperatures leads to values $\delta_{\mathrm{H}}=0$ even at $400 \mathrm{~K}$ for $\mathrm{Si}$; at $190 \mathrm{~K}$ for Ge; at $480 \mathrm{~K}$ for diamond and at $240 \mathrm{~K}$ for the $\mathrm{Al}_{63} \mathrm{Cu}_{25} \mathrm{Fe}_{12}$ quasicrystal. However, the indentation in a wide temperature range adjacent to $0 \mathrm{~K}$ in these materials is accompanied by a phase transition, which provides a nonzero value of $\delta_{\mathrm{H}}(0)$ in them.

It is shown that a decrease in the plasticity $\delta_{\mathrm{H}}$ with decreasing temperature in a wide temperature range which is adjacent to $0 \mathrm{~K}$ and usually includes room temperature is inversely proportional to the product $\mathrm{V} \cdot \mathrm{E}$, where $\mathrm{V}$ is the activation volume and $\mathrm{E}$ is Young's modulus. 
For FCC metals, for which $\mathrm{V}$ is very large, the decrease in $\delta_{\mathrm{H}}$ appears to be insignificant.

Materials differing in the type of the interatomic bond and atomic structure differ substantially in plasticity at $0 \mathrm{~K} \delta_{\mathrm{H}}(0)$, which can be considered to be the important characteristic of a material under the dislocation mechanism of deformation (with above-barrier motion of dislocations in the absence of thermal vibrations of atoms) and must be discussed for every material simultaneously with the value of the Peierls Nabarro stress or, more precisely, with the yield stress at $0 \mathrm{~K}$ $\sigma_{\mathrm{S}}(0)$, which, besides the Peierls - Nabarro stress, includes the athermal component of the yield stress.

For the adequate characterization of the mechanical behavior of the materials, knowledge of the strength characteristics in the form of the yield stress $\sigma_{\mathrm{S}}(0)$ or hardness $\mathrm{HV}(0)$, the plasticity characteristic $\delta_{\mathrm{H}}(0)$, and dependences of these properties on temperature is necessary.

\section{References}

[1] M. P. Markovets, Definition of the Mechanical Properties of Metals by Hardness. Moscow: Mashinostroenie, 1979, 191 p., in Russian.

[2] H. M. Pollock, Nanoindentation, Friction, Lubrication, and Wear, Metals Handbook, vol. 18, P. J.Blau, Eds. ASM International, 1992, pp. 419-429.

[3] Yu. V. Milman, B. A. Galanov, and S. I. Chugunova, "Plasticity characteristic obtained through hardness measurement" (overview 107), Acta metall mater, vol. 41, no.9, pp. 2523-2532, 1993.

[4] B. A. Galanov, Yu. V. Milman, S.I. Chugunova, and I. V. Goncharova, "Investigation of mechanical properties of high-hardness materials by indentation", Superhard Mater, no.3, pp. 25-38, 1999.

[5] Yu. V. Milman, S. I. Chugunova, and I. V. Goncharova. "Plasticity chracteristic obtained by indentation technique for crystalline and noncrystalline materials in the wide temperature range", High Temp Mater Process, vol. 25, no. 1-2, pp. 39-46, 2006.

[6] A. Byakova, Yu. Milman, and A. Vlasov, "High performance ceramic coatings for cutting tool - Perspectives in improvement of coating mechanical properties", in: Proc. 8th CIRP Int. Workshop on Modeling of Machining Operations, Chemnitz, Germany, R. Neugebauer, Ed. Chemnitz: Fraunhofer Inst. Werkzeugmaschinen und Umformtechnik, 2005, pp. 559-568.

[7] Yu. Milman, "Plasticity characteristic obtained by indentation", J Phys D: Appl Phys, vol. 41, 074013, 9 p., 2008.

[8] B. Bozzini, M. Boniardi, A. Fanigliulo, and F. Bogani, "Tribological properties of electroless Ni-P/diamond composite films", Mater Res Bull, vol. 36, iss.11, pp. 1889-1902, 2001.

[9] P. H. Boldt, G. C. Weatherly, and J. D. Embury, "A tranmission electron microscope study of hardness indentations in $\mathrm{MoSi}_{2}$ ", J Mater Res, vol. 15, no.4, pp. 1025-1031, 2000.
[10] J. B. Qiang, W. Zhang, G. Xie, H. Kimura, C. Dong, and A. Inoue, "An in situ bulk $\mathrm{Zr}_{58} \mathrm{Al}_{9} \mathrm{Ni}_{9} \mathrm{Cu}_{14} \mathrm{Nb}_{10}$ quasicrystal-glass composite with superior room temperature mechanical properties”, Intermetallics, vol. 15, pp. 1197-1201, 2007.

[11] F. Meng, B. Wang, F. Ge, and F. Huang, "Microstructure and mechanical properties of Ni-alloyed $\mathrm{SiC}$ coatings", Surface\&Coatings Tech, vol. 213, pp. 77-83, 2012.

[12] P. Mogilevsky, "Indentification of slip systems in $\mathrm{CaWO}_{4}$ scheelite", Phil Mag, vol. 85, no.30, pp. 3511-3539, 2005.

[13] Y. Estrin, N. V. Isaev, S. V. Lubenets, S. V. Malykhin, A. T. Pugachov, V. V. Pustovalov, E. N. Reshetnyak, V. S. Fomenko, L. S. Fomenko, S. E. Shumilin, M. Janecek, and R. J. Hellmig, "Effect of microstructure on plastic deformation of $\mathrm{Cu}$ at low homologous temperatures", Acta Mater, vol. 54, pp. 5581-5590, 2006.

[14] G. Sharma, R. V. Ramanujan, T. R. G. Kutty, and N. Prabhu, "Indentation creep studies of iron aluminide intermetallic alloy" Intermetallics, vol. 13, pp. 47-53, 2005.

[15] M. Gogebakan, B. Avar, and M. Tarakci, "Microstructures and mechanical properties of conventionally solidified $\mathrm{Al}_{63} \mathrm{Cu}_{25} \mathrm{Fe}_{12}$ alloys", $\mathrm{J}$ Alloys and Compounds, vol. 509S, pp. S316-S319, 2011.

[16] N. K. Mukhopadhyay, G. C. Weatherly, and J. D. Embury, “An analysis of microhardness of single-quasicrystals in the Al-Cu-Co-Si system", Mater Sci Eng A, vol. 315, pp. 202-210, 2001.

[17] en.wikipedia.org/wiki/Plasticity_(physics).

[18] A. L. Roytburd, Plasticity of crystals, Physical Encyclopedic Dictionary. Moscow: Soviet Encyclopaedia, 1983, p. 548, in Russian.

[19] A. Kelly. Strong Solids. Oxford: Clarendon Press, 1973, 261 p.

[20] J. J. Gilman, "Electronic basis of hardness and phase transformations (covalent crystals)", J Phys. D: Appl Phys, vol. 41, 074020, 5 p., 2008.

[21] Yu. V. Milman, S. Luyckx, V. A. Goncharuk, and Y. T. Northrop, "Results from bending tests on submicron and micron WC-Co grades at elevated temperatures", Int. J Ref Met Hard Mater, vol. 20, pp. 71-79, 2002.

[22] Yu. Milman, S. Dub, and A. Golubenko, "Plasticity characteristic obtained through instrumental indentation", Mater Res Soc Symp Proc, vol. 1049, pp. 123-128, 2008.

[23] I. V. Gridneva, Yu. V. Milman, and V. I. Trefilov, "On the Mechanical Properties of Crystals with Covalent Bond", Phys stat sol, vol. 36, no. 59, pp. 59-67, 1969.

[24] V. I. Trefilov, V. A. Borisenko, G. G. Gnesin, I. V. Gridneva, Yu. V. Milman, and S. I. Chugunova, "On the phase transition under pressure in silicon carbide", Sov Phys Dokl, vol. 23, pp. 207-208, 1978.

[25] Yu. V. Milman and E. S. Koba, "On the dislocation mechanism of plastic flow in metallic glasses", Sci Sintering, vol. 31, pp. 65-82, 1999.

[26] Yu. V. Milman, O. E. Sklyarov, V. I. Trefilov, and A. A. Udovenko, "Device PMTN for microhardness measurements at low temperatures under a layer of a cooling liquid", Trudy Metrologicheskikh Institutov SSSR, vol. 91, pp. 167-169, 1967, in Russian. 
[27] I. N. Frantsevich, F. F. Voronov, and S. A. Bakuta, Elastic Constants and Modulus of Metals and Non-Metals. Kiev: Naukova Dumka, 1982, 286 p., in Russian.

[28] R. A. Andrievsky, A. G. Lanin, and G. A. Rymashevsky, Strength of Refractory Compounds. Moscow: Metallurgija, 1974, 232 p., in Russian.

[29] V. V. Pustovalov and S. E. Shumilin, "Plastic deformation and super-conducting properties of aluminium alloys at temperatures 0.5-4.2K", The Physics of Metals and Metallographs (USSR), vol.62, pp. 171-179, 1986.

[30] R. P. Reed, "Aluminium 2. A review of deformation properties of high purity aluminium and dilute aluminium alloys", Cryogenics, vol. 12, iss. 4, pp. 259-291, 1972.

[31] Z. Huang, L. Y. Gu, and J. R. Weertman, "Temperature dependence of hardness of nanocrystalleve copper in low-temperature range", Scrip Mater, vol. 37, iss. 7, pp. 1071-1075, 1997.

[32] V. I. Trefilov, Yu. V. Milman, and S. A. Firstov. Physical Basis of Strength of Refractory Metals. Kiev: Naukova Dumka, 1975, 315 p., in Russian.

[33] Yu. V. Milman and V. I. Trefilov, "Physical nature of the temperature dependence of yield stress", Powder Metall Met Ceram, vol. 49, no. 7-8, pp. 374-385, 2010.

[34] D. Tabor. The Hardness of Metals. Oxford Clarendon Press, 1951, $130 \mathrm{p}$.

[35] K. J. Johnson. Contact Mechanics. Cambridge: Cambridge University Press, 1985, 510 p.

[36] Yu. V. Milman, "Structure and mechanical properties of materials in the temperature ranges of cold, warm and hot deformation", Mater Sci Forum, vol. 426-432, pp. 4399-4404, 2003.

[37] V. I. Trefilov, Yu. V. Milman, and I. V. Gridneva, "Characteristic temperature of deformation of crystalline materials", Crys Res and Technol, vol. 19, no. 3, pp. 413-421, 1984.

[38] P. H. Thornton, R. G. Davies, and T. L. Johnston, "The temperature dependence of the flow stress of the $\gamma^{\prime}$ phase based upon $\mathrm{Ni}_{3} \mathrm{Al}^{\prime}$, Metall Trans, vol. 1, iss.1, pp. 207-218, 1970.

[39] Yu. V. Milman, "Deformation mechanisms, microstructure and mechanical properties of nanoscale crystalline and noncrystalline materials in different temperature ranges", Mater Res Soc Symp Proc, vol. 1297, pp. 77-82, 2011.

[40] I. V. Gridneva, Yu. V. Milman, and V. I. Trefilov, "Phase transition in diamond structure crystals at hardness measurement", Phys Status Solidi (a), vol. 14, pp. 177-182, 1972.
[41] Yu. V. Milman, S. I. Chugunova, I. V. Goncharova, T. Chudoba, W. Lojkowski, and W. Gooch, "Temperature dependence of hardness in silicon-carbide ceramics with different porosity", Int J Refractory Met Hard Mater, vol. 17, pp. 361-368, 1999.

[42] Yu. V. Milman, D. V. Lotsko, A. N. Belous, and S. N. Dub, "Quasicrystalline materials. Structure and mechanical properties", in: Functional Gradient Materials and Surface Layers Prepared by Fine Particles Technology, M.-I. Baraton and I. Uvarova, Eds. Kluwer Acad. Publ., Kiev, 2001, pp. 289-296.

[43] Yu. V. Milman, D. V. Lotsko, S. N. Dub, A. I. Ustinov, S. S. Polishchuk, and S. V. Ulshin, "Mechanical properties of quasicrystalline Al-Cu-Fe coatings with submicron-sized grains", Surface \& Coatings Techn, vol. 201, pp. 5937-5943, 2007.

[44] H. V. Swygenhoven and J. R. Weertman, "Deformation in nanocrystalline metals", Mater Today, vol. 9, iss.5, pp. 24-31, 2006.

[45] T. Suzuki and T. Ohmura, "Ultra-microundentation of silicon at elevated temperatures", Phil Mag A, vol. 74, no.5, pp. 1073-1084, 1996.

[46] S. J. Lloyd, A. Castellero, F. Giuliani, Y. Long, K. K. McLaughlin, J. M. Molina-Aldareguia, N. A. Stelmashenko, L. J. Vandeperre, and W. J. Clegg, "Observations of nanoindents via cross-sectional transmission electron microscopy: a survey of deformation mechanisms", Proc R Soc A, vol. 461, pp. 2521-2543, 2005.

[47] V. Domnich, Yu. Gogotsi, and S. Dub, "Effect of phase transformations on the shape of the unloading curve in the nanoindentation of silicon", Appl Phys Lett, vol. 76, no.16, pp. 2214-2216, 2000.

[48] M. M. Chaudri, M. M. O. Khayyat, D. G. Hasko, "Investigations of the indentation-induced crystallographic phase changes in silicon using Raman spectroscopy", Surface Review and Letters, vol. 14, no.4, pp.719-723, 2007.

[49] V. Domnich, Y. Aratyn, W. M. Kriven, Yu. Gogotsi, "Temperature dependence of silicon hardness: Experimental evidence of phase transformations", Rev Adv Mater Sci, vol. 17, no.1-2, pp. 33-41, 2008.

[50] Yu. V. Milman, D. B. Miracle, S. I. Chugunova, I. V. Voskoboinik, N. P. Korzhova, T. N. Legkaya, and Yu. N. Podrezov, "Mechanical behaviour of Al3Ti intermetallic and $\mathrm{L}_{2}$ phases on its basis", Intermetallics, vol.9, pp. 839-845, 2001. 